\title{
COMPETENCIAS COGNITIVAS EN EDUCACIÓN SUPERIOR ${ }^{1}$
}

\section{COGNITIVE COMPETENCES IN HIGHER EDUCATION}

Edith Castelán García

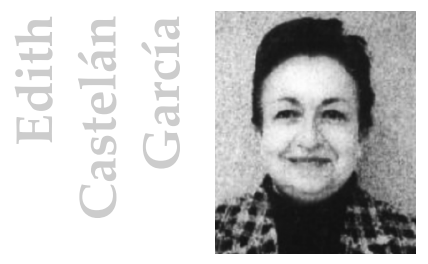

Profesora de Educación Preescolar, Escuela Nacional para Maestras de Jardines de Niños. Licenciada en Pedagogía, SEP. Estudios de Licenciatura en Historia, Universidad Nacional Autónoma de México (UNAM). Estudios de Maestría en Educación Familiar, Universidad Panamericana. Diplomado en Antropología Filosófica, Universidad Panamericana.

Correo electrónico: [ecastela@yahoo.com.mx].

Ma. Luisa Sanz de Acedo Lizarraga, profesora titular del Departamento de Psicología y Pedagogía de la Universidad Pública de Navarra, plantea la necesidad de formar personas reflexivas, que comprendan la información, la evalúen y actúen con base en ella; capaces de aminorar las grandes desigualdades educativas y económicas existentes, y de crear un entorno social caracterizado por el bienestar, la justicia y la equidad.

El enfoque que ofrece la autora sobre las competencias cognitivas en educación superior, parte del estudio sobre las competencias genéricas que propone la Unión Europea (Proyecto Tuning) para brindar, tanto a profesores como a los propios estudiantes del nivel superior, un conocimiento teórico y práctico sobre el proceso enseñanza-aprendizaje de las mismas, consideradas como las más relevantes y complejas del ser humano.

1 Ma. Luisa Sanz de Acedo Lizarraga. Competencias cognitivas en educación superior. Narcea Ediciones, 2010, Madrid, 159 p. 
$\mathrm{Al}$ inicio define a la competencia como «[...] la capacidad que se proyecta en la forma en que una persona utiliza todos sus recursos personales (conocimientos, actitudes, habilidades y experiencias) para resolver adecuadamente una tarea en un contexto definido»... «La competencia pone de manifiesto el nivel de desarrollo alcanzado en diferentes capacidades y contribuye a mejorarlo» ${ }^{2}$; al mismo tiempo puntualiza los términos aptitud, habilidad, destreza, que forman parte de la «estructura mental del ser humano y se integran en el proceso mental por excelencia: el pensamiento» ${ }^{3}$.

Configura su obra en siete capítulos en donde indistintamente encontramos el empleo de los términos competencia, capacidad y habilidad, versatilidad de empleo que justifica por su enfoque cognitivo y su desigual grado de amplitud y complejidad «la competencia de solucionar problemas es más difícil que la de comparar información» ${ }^{4}$.

En el primer capítulo, Alcances del constructo competencia, analiza su trascendencia, asociándola con componentes mentales, culturales, actitudinales y conductuales:

Una persona competente es aquella que posee la creatividad, la disposición, y las cualidades necesarias para hacer algo cada vez mejor y justificar lo que hace, es decir su conducta ${ }^{5}$.

Argumenta con claridad y sencillez el enfoque de la educación centrada en competencias cuyo fin son los aprendizajes necesarios para que «el estudiante actúe de manera activa, responsable y creativa en la construcción de su proyecto de vida, tanto personal y social como profesional» ${ }^{6}$.

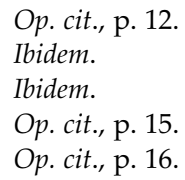


Explica cuidadosamente los pasos para la redacción de las competencias y se refiere a la naturaleza de las competencias genéricas organizadas en cuatro grupos: cognitivas (relacionadas con el sistema intelectual del ser humano); socio/afectivas (convivencia con otras personas); tecnológicas (búsqueda y manejo de información a través de las tecnologías de la información), y metacognitivas (conciencia de los propios procesos cognitivos).

La autora caracteriza al pensamiento humano y clasifica el perfil de las competencias cognitivas en cinco grupos. Sobre la incorporación de las competencias en la enseñanza universitaria, define la naturaleza modificable, dinámica y plástica de la competencia y la dificultad de interpretar su eficacia proponiendo tres criterios para comprobar su impacto.

Al reconocer el objetivo de la evaluación de competencias como «valorar la calidad de los aprendizajes conseguidos por el estudiante tanto en el desarrollo de las competencias como en la adquisición de contenidos académicos» ${ }^{7}$, brinda orientaciones generales sobre la evaluación y propone el portafolios como instrumento de evaluación continua que contiene, en el caso del alumno, «una síntesis de todo su historial académico, en una o varias asignaturas» ${ }^{8}$, y en el caso del portafolios del profesor, incluye información sobre la materia, organización didáctica, interpretación de resultados y aprendizaje para valorar cambios para el siguiente curso.

En el segundo capítulo Competencias necesarias para comprender la información: pensamiento comprensivo, analiza las competencias requeridas para

[...] comprender, clarificar e interpretar la información [...]. ayudan a hacer un buen uso de la misma y alcanzar un aprendizaje significativo, con sentido, basado en la relación de los conocimientos previos con la nueva información 9 .

$7 \quad$ Ibidem, p. 34.

$8 \quad$ Ibidem, p. 37.

9 Ibidem, p. 41. 
Desarrolla una definición operacional de cada una de las seis competencias del pensamiento comprensivo: comparar, clarificar, analizar, sintetizar, secuenciar y descubrir razones, adjuntando su representación gráfica y ejemplos de la misma en distintas áreas, puntualizando qué hace la mente cuando las practica.

En el tercer capítulo presenta a las Competencias necesarias para evaluar la información. Es el pensamiento crítico, citando a Halpern (2003):

[...] dirigido, razonado y propositivo, centrado en la comprensión de algo, la formulación de inferencias, el cálculo de probabilidades, la toma de decisiones, la resolución de problemas y la evaluación de sus propios procesos ${ }^{10}$.

Define a las competencias del pensamiento crítico que analiza e identifica como: 1) investigar la fiabilidad de las fuentes; 2 ) interpretar las causas; 3) predecir efectos; 4) razonar analógicamente, y 5) razonar deductivamente. Asimismo, las representa gráficamente y puntualiza los pasos pertinentes para practicarlas, integrando en cada una algunos ejemplos pertinentes.

En el cuarto capítulo, Pensamiento creativo, se analizan las competencias necesarias para generar la información; la autora, citando a Ward, las define como:

[...] una extensión del pensamiento creativo y crítico. [...] la persona se adapta, improvisa, aconseja, planifica, diseña, emprende, innova y propone ideas que contribuyen al bien social ${ }^{11}$.

Identifica cuatro fases del impulso creativo, y un conjunto de características asociadas a los ámbitos del pensamiento, la personalidad, la motivación y el conocimiento. Destaca que la creatividad no es únicamente personal, sino producto de contribuciones grupales e identifica cinco competencias del pensamiento creativo: generar 
ideas, establecer relaciones, producir imágenes, crear metáforas y emprender metas; las caracteriza, representa gráficamente, cuestiona y ejemplifica.

En el quinto capítulo, Toma de decisiones y solución de problemas, analiza a las competencias definidas como las más complejas, denominadas también competencias superiores: competencias que han de ser ejercitadas y estimuladas en todos los planes y programas de estudio de educación superior; identifica cuatro fases en el proceso de decisión y seis en el proceso de toma de decisiones. Detalla las características de las decisiones grupales y clarifica los factores que intervienen en la decisión.

Apunta como subcompetencias asociadas a la toma de decisión, las siguientes: 1) determinar el objeto a decidir; 2) considerar opciones; 3 ) predecir consecuencias, y 4) elegir la mejor opción. Define a cada subcompetencia integrando su representación gráfica, comentarios y ejemplos en distintas áreas.

Identifica como subcompetencias en la solución de problemas: 1) definir el problema; 2) generar soluciones; 3) predecir consecuencias; 4) elegir la mejor solución; 5) verificar la solución, y 6) evaluar los resultados.

La tarea de enseñar estos procesos complejos, significa un gran reto para los profesores, señala la autora, aunque no es imposible de alcanzar, puesto que son factibles de estimular.

Los Recursos cognitivos: metacognición, autorregulación y transferencia, se presentan en el sexto capítulo. La autora indica que el concepto metacognición se atribuye a Flavell y se refiere a la actividad mental centrada en el propio funcionamiento psicológico que consiste en «reflexionar sobre cómo uno mismo aprende, razona, crea, decide, actúa y siente, identificando el tipo de competencia utilizada» ${ }^{12}$.

$12 \quad$ Ibidem, p. 113. 
Con base en Brown, señala como los tres principales componentes de la metacognición, los siguientes: 1) la conciencia de los propios procesos mentales; 2) el conocimiento de las propias capacidades cognitivas y afectivas, y de cómo se relacionan entre sí, y 3) la regulación de la mente y de la conducta.

Define a la autorregulación como

[...] un proceso muy activo y práctico, interno y con proyección externa, más consciente que inconsciente y lleno de juicios y adaptaciones, que dirige tanto al pensamiento como a la conducta ${ }^{13}$.

Identifica como fases de la actividad a la planificación (antes), la monitorización (durante) y la evaluación (después).

A la transferencia la define como «aprender algo en una circunstancia y aplicarlo después en otra diferente» ${ }^{14}$. El docente que estimula y el estudiante que practica estas competencias aumentan su potencial intelectual, y desarrollan habilidades intelectuales de orden superior que les permitirán acceder a cualquier tipo de conocimiento.

En el último capítulo, Enseñar competencias cognitivas: algunas formas de intervención, se ofrecen sugerencias metodológicas para el desarrollo de las competencias cognitivas analizadas: Método «Pensar activamente en entornos académicos», cómo aprender una asignatura, utilidad de las preguntas en el aprendizaje, estimulación de la creatividad, papel de las estrategias en el aprendizaje, competencias cognitivas, nuevas tecnologías: un modelo de guía docente.

Valorar el desarrollo de competencias cognitivas en el aprendizaje de estudiantes del nivel superior implica la intencionalidad del docente de desarrollar en sí mismo dichas competencias para lograr 
impulsarlas en los estudiantes. Formar para la vida y para la profesión es el objetivo siempre presente en la obra que finaliza afirmando:

La calidad de nuestra vida, la calidad de lo que hacemos y producimos dependen precisamente de la calidad de nuestras competencias, la proyección de las mismas en la sociedad y el uso eficiente de las TIC ${ }^{15}$. 